\title{
Adaptation of spring-sown chickpea to the Mediterranean basin. II. Factors influencing yield under drought
}

\author{
S.N. Silim and M.C. Saxena \\ International Center for Agricultural Research in the Dry Areas (ICARDA), P.O. Box 5466. \\ Aleppo, Syria
}

(Accepted 23 February 1993)

\begin{abstract}
Drought during the late vegetative and reproductive stages of development is the major constraint to the productivity of spring-sown chickpea in the rainfed farming systems of West Asia and North Africa. This paper examines the contribution of crop traits to yield under drought and determines the relative contributions of drought escape, yield potential and a drought response index (DRI) to such yield.

In years with mild drought ( $1986 / 87$ and $1987 / 88)$, high biomass, high yield potential and high harvest index were highly correlated with grain yield. During the severe drought of $1988 / 89$, early flowering and low straw yield, high harvest index, yield potential, pod and seed number and seed mass were correlated with rainfed grain yield.

Differences among chickpea cultivars in rainfed (drought) yield were partitioned into drought escape, yield potential and DRI. Drought escape accounted for $41 \%$ in $1986 / 87,37 \%$ in $1987 / 88$ and $69 \%$ in $1988 / 89$; yield potential accounted for $47 \%, 37 \%$ and $1 \%$, respectively; and DRI accounted for $4 \%, 17 \%$ and $17 \%$ of the variations, respectively. The three factors combined explained an average of $90 \%$ of the variability in grain yield. The DRI was used to quantify tolerance or susceptibility of a cultivar independently of drought escape (early flowering) and yield potential. Of the traits which were significantly associated with drought yield, high harvest index, large number of pod and high seed mass were associated with drought escape (early flowering), while deep root system, high leaf water potential at dawn and large number of seeds were associated with drought tolerance (DRI).
\end{abstract}

\section{INTRODUCTION}

In the Mediterranean areas of West Asia and North Africa (WANA), where rainfall is in winter, chickpea is normally sown in spring in areas with at least $400 \mathrm{~mm}$ annual average rainfall. From the late vegetative stage of growth until maturity, the crop experiences ever-increasing evaporative demand be-

Correspondence to (Present address): S.N. Silim, International Crops Research Institute for the Semi-Arid Tropics (ICRISAT), P.O. Box 39063, Nairobi, Kenya.

Submitted as Journal Article No. 1272 by International Crops Research Institute for the SemiArid Tropics (ICRISAT). 
cause of high temperatures. Soil moisture reserve is rarely adequate to meet water requirement of the crop and considerable drought stress is experienced, which limits grain yield (Saxena et al., 1990).

The emphasis in spring chickpea improvement at ICARDA (International Center for Agricultural Research in the Dry Areas) is on the development of cultivars that give high and stable yields in the WANA region, where the crop depends on variable amounts of moisture stored in the soil profile and where terminal drought is a major production constraint. Presently, grain yield is the main selection criterion for drought resistance. Better adapted and higher yielding barley cultivars can be bred more efficiently and effectively if attributes that confer drought resistance are identified and used as selection criteria (Acevedo and Ceccarelli, 1989). In lentil, early growth vigour, establishment of high ground cover early in the season, light green colour during early vegetative growth and early flowering and maturity are attributes associated with high yield under drought (Silim et al., 1993). Similarly, in wheat (Fischer and Wood, 1979) and pearl millet (Bidinger et al., 1987a), early flowering was reported as an important trait for high yield under drought. Bidinger et al. (1987b) used a drought response index (DRI) to describe the response of individual cultivars of pearl millet to drought, independently of phenology and yield potential (non-stress yield), and determined attributes associated with DRI.

This paper examines the response of spring-sown chickpea cultivars of diverse origin to terminal drought, estimates the relative importance of drought escape, yield potential and DRI in adaptation to drought and determines traits that contribute to tolerance to drought independently of phenology (drought escape) and yield potential.

\section{MATERIALS AND METHODS}

\section{Field experiments}

The details of the field experiments on which the analyses of response to drought are based are described fully in the first paper (Silim and Saxena, 1993 ). In summary: the trials were conducted at Tel Hadya in northern Syria using 16, 17 and 20 chickpea cultivars of diverse origin in 1986/87, 1987/88 and $1988 / 89$, respectively. The cultivars (lines) used in the study included landraces from WANA and the Indian sub-continent, and high-yielding cultivars bred at ICARDA and ICRISAT (International Crops Research Institute for the Semi-Arid Tropics) in India. A line-source sprinkler irrigation system was used to create a soil moisture supply gradient. Areas closest to the sprinklers received the highest supplemental moisture supply and those far away none, these latter thus depending on residual moisture from rainfall stored in the soil. The grain yields from the rainfed area were the drought- 
stress yields and those from areas closest to the line-source sprinkler, yield potential.

The yield response of chickpea cultivars to moisture supply and the traits associated with variations in grain yield were presented in the previous paper (Silim and Saxena, 1993).

\section{Factors contributing to drought yield}

The relationships between drought yield and yield components, phenology and yield potential were examined first. Similar correlations for the yield potential treatment were also examined to determine whether traits associated with high grain yield were similar under drought and non-stressed conditions. According to Bidinger et al. (1987b), grain yield under drought is a function of time to flowering, yield potential and drought response. If drought resistance is considered a consequence of advantages conferred by one or more physiological or morphological characteristics (Turner, 1982) and can be manipulated in the breeding program as an independent genetic trait (Blum, 1979; Quisenberry, 1982; Richards, 1982), drought resistance should be assessed independently of the effects of time of flowering and yield potential. Therefore, we have quantified the response of each cultivar to drought stress independently of drought escape (early flowering) and yield potential, using the drought response index (DRI) as reported by Bidinger et al. (1987b), based on multiple regression:

$Y_{0}=a-b F+c Y_{\mathrm{i}}$ and

$\begin{aligned} & \text { Drought response index } \\ & (\text { Standard residual })\end{aligned}=\frac{Y_{0}-\hat{Y}_{0}}{\text { Standard error of } \hat{Y}_{0}}$

where $Y_{0}=$ yield under drought; $\hat{Y}_{0}=$ regression estimate of yield under drought; $Y_{\mathrm{i}}=$ yield potential; $F=$ days to flowering.

The relative contributions of drought escape, yield potential and DRI were then determined. Finally, drought escape and DRI for each cultivar in each year were correlated with some of the traits measured, to determine whether they were related to either of the two.

\section{RESULTS AND DISCUSSION}

\section{Climate}

Weather at Tel Hadya during the period of study was described by Silim and Saxena (1993). Briefly, the seasons provided contrasts in temperature and rainfall and hence drought stress experienced by the crop. The 1986/87 season was a low-stress season favourable for crop growth; precipitation was $359 \mathrm{~mm}$, slightly higher than the long-term average for Tel Hadya ( $330 \mathrm{~mm}$ ), and the temperatures during the March-May period were lower than the long- 
term average. The $1987 / 88$ season again was favourable, precipitation was $504 \mathrm{~mm}$, the wettest since $1940 / 41$, with temperatures similar to or slightly lower than the long-term average. In contrast, drought was intense during the 1988/89 season; total precipitation was only $234 \mathrm{~mm}$, with most received in the November-January period, and the rise in temperatures was fast, with temperatures in March-May period higher than the long-term average. This provided an opportunity to determine whether traits associated with grain yield were similar in all seasons or were environment dependent and only evident in particular seasons.

\section{Grain yield under drought stress}

Details of grain yield under drought for the period of study are given in Silim and Saxena (1993). In summary, the range in grain yield was 0.636-

\section{TABLE 1}

Ranges in phenology, grain yield and yield components of chickpea in the unirrigated and irrigated treatments at Tel Hadya, northern Syria for three seasons

\begin{tabular}{|c|c|c|c|c|}
\hline & \multicolumn{2}{|c|}{ Unirrigated } & \multicolumn{2}{|c|}{ Irrigated } \\
\hline \multicolumn{5}{|l|}{$1986 / 87$} \\
\hline Days to flowering & 53 & -84 & 53 & -84 \\
\hline Days to maturity & 87 & -101 & 97 & -116 \\
\hline Grain yield ( $t /$ ha $)$ & $0.6 ?$ & $6-1.231^{* * *}$ & 1.2 & $35-2.504^{* * *}$ \\
\hline Straw yield $(\mathrm{t} / \mathrm{ha})$ & 0.65 & $0-1.783^{* * *}$ & 1.4 & $43-3.370^{* * *}$ \\
\hline Biomass ( $t /$ ha $)$ & 1.32 & $3-2.523^{* * *}$ & 3.1 & $27-5.874^{* * *}$ \\
\hline Harvest index & 0.42 & $-0.60^{* *}$ & 0.3 & $-0.56^{* *}$ \\
\hline Pods $/ \mathrm{m}^{2}$ & 389 & $-862 * *$ & 638 & $-1933^{* * *}$ \\
\hline Seeds $/ \mathrm{m}^{2}$ & 451 & $-1262^{* *}$ & 858 & $-3687^{* * *}$ \\
\hline 100-seed mass $(\mathrm{g})$ & 17.4 & $-47.8^{* * *}$ & 13.7 & $-48.7^{* * * *}$ \\
\hline \multicolumn{5}{|l|}{$1987 / 88$} \\
\hline Days to flowering & 45 & -59 & 45 & -59 \\
\hline Days to maturity & 75 & -96 & 78 & -98 \\
\hline Grain yield $(t / h a)$ & 0.80 & $3-1.364^{* * * *}$ & 1.3 & $3-2.027^{* * * *}$ \\
\hline Straw yield ( $t /$ ha $)$ & 0.72 & $7-1.625^{* * * *}$ & $1.0^{\circ}$ & $9-2.756^{* * * *}$ \\
\hline Biomass $(\mathrm{t} / \mathrm{ha})$ & 1.54 & $2-2.893^{* * *}$ & 2.3 & $6-4.578^{* * *}$ \\
\hline Harvest index & 0.33 & $-0.60^{* * *}$ & 0.39 & $-0.57^{* *}$ \\
\hline Pods $/ \mathrm{m}^{2}$ & 248 & $-697^{* * *}$ & 428 & $-950^{* * *}$ \\
\hline Seeds $/ \mathrm{m}^{2}$ & 268 & $-880^{* * * *}$ & 503 & $-1160^{* * *}$ \\
\hline 100 -seed mass $(\mathrm{g})$ & 18.5 & $-48.3^{* * * *}$ & 18.0 & $-43.3^{* * *}$ \\
\hline \multicolumn{5}{|l|}{$1988 / 89$} \\
\hline Days to flowering & 44 & -63 & 44 & -63 \\
\hline Days to maturity & 67 & -85 & 84 & -97 \\
\hline Grain yield ( $\mathrm{t} / \mathrm{ha})$ & 0 & $-0.658^{* * *}$ & \multicolumn{2}{|c|}{$0.718-2.708^{* * *}$} \\
\hline Straw yield ( $t /$ ha $)$ & \multicolumn{2}{|c|}{$0.558-1.885^{* *}$} & \multicolumn{2}{|c|}{$1.869-5.795^{* * *}$} \\
\hline Biomass $(t / h a)$ & \multicolumn{2}{|c|}{$0.781-1.955^{* * *}$} & \multicolumn{2}{|c|}{$3.777-6.513^{* * * x}$} \\
\hline Harvest index & 0 & $-0.46^{*}$ & 0.1 & $-0.52^{* * *}$ \\
\hline
\end{tabular}

Significance: $* *=P<0.01 ; * * * P<0.001$. 
$1.231 \mathrm{t} / \mathrm{ha}$ in $1986 / 87 ; 0.803-1.364 \mathrm{t} / \mathrm{ha}$ in $1987 / 88$; and $0-0.658 \mathrm{t} / \mathrm{ha}$ in $1988 / 89$ (Table 1 ), and the respective mean grain yields for each year were $0.984 \mathrm{t} / \mathrm{ha}, 1.099 \mathrm{t} / \mathrm{ha}$ and $0.187 \mathrm{t} / \mathrm{ha}$.

\section{Factors influencing grain yield under drought stress}

The correlations between drought yield and various crop traits varied with year (Table 2 ). Correlations between drought-stress grain yield and biomass were positive and significant only during the low-stress years, 1986/87 $\left(r=0.685^{* * *}\right)$ and $1987 / 88\left(r=0.718^{* * *}\right)$ and those between drought grain yield and harvest index were significant in all three years $\left(r=0.509^{*}, 0.521^{*}\right.$ and $0.950^{* * *}$, respectively for $1986 / 87,1987 / 88$ and $\left.1988 / 89\right)$, hence strongest in the high-stress season. The results for $1986 / 87$ and $1987 / 88$ are similar to those reported by Saxena et al. (1990) for chickpea and Silim and Saxena (1992) for faba bean, i.e. under favourable growing conditions, high biomass production is a major pre-requisite for attaining high grain yields, but this should be accompanied by a high harvest index. However, in a nonstress treatment, during the same period (1986/87 and 1987/88), the major trait associated with high grain yield was high biomass (Table 2 ). Probably in spring-sown chickpea, when thermal and moisture regimes are favourable, attainment of high grain yield is associated with high biomass production; and at low to intermediate levels of moisture and thermal stresses (as in the rainfed treatment in 1986/87 and 1987/88), both high biomass production

\section{TABLE 2}

Correlations between drought stress grain yield (D) and potential grain yield (I) and some plant traits of spring-sown chickpea at Tel Hadya, northern Syria for three seasons

\begin{tabular}{|c|c|c|c|}
\hline Traits & $1986 / 87$ & $1987 / 88$ & $1988 / 89$ \\
\hline Days to flower: D & -0.173 & 0.431 & $-0.842^{* * *}$ \\
\hline 1 & 0.345 & 0.130 & $-0.656^{* *}$ \\
\hline Days to mature: $\mathrm{D}$ & 0.085 & -0.268 & $-0.562^{* *}$ \\
\hline I & 0.449 & 0.195 & 0.432 \\
\hline Biomass: D & $0.685^{* *}$ & $0.718^{* * *}$ & 0.252 \\
\hline I & $0.758^{* * *}$ & $0.827^{* * *}$ & -0.302 \\
\hline Straw yield: D & 0.029 & 0.245 & $-0.609^{* * *}$ \\
\hline Harvest index: D & $0.509^{*}$ & $0.521^{*}$ & $0.950^{* * *}$ \\
\hline 1 & 0.229 & -0.022 & $0.810^{* * *}$ \\
\hline Irrigated (potential) grain yield: D & $0.688^{* *}$ & $0.593^{* *}$ & $0.546^{* *}$ \\
\hline Pods $/ \mathrm{m}^{2}: \mathrm{D}$ & -0.287 & 0.053 & $0.878^{* * *}$ \\
\hline 1 & -0.356 & -0.192 & $-0.450^{*}$ \\
\hline Seeds $/ \mathrm{m}^{2}: \mathrm{D}$ & -0.369 & -0.064 & $0.887^{* * *}$ \\
\hline I & -0.402 & -0.185 & -0.381 \\
\hline 100 -seed mass $(\mathrm{g}): \mathrm{D}$ & $0.482^{*}$ & 0.342 & $0.461^{* * *}$ \\
\hline I & $0.525^{*}$ & $0.549^{*}$ & 0.071 \\
\hline
\end{tabular}

Significance: ${ }^{*}=P<0.05 ;{ }^{* *}=P<0.01 ;{ }^{* * *}=P<0.001$. 
and partitioning of a high proportion to the grain (high harvest index ) become major factors contributing to high grain yield. At high levels of stress $(1988 / 89)$, however, partitioning becomes the major factor contributing to high grain yield (Table 2). Correlations between drought grain yield and phenology (days to flowering and maturity) and between drought grain yield and straw yield were highly significant and negative, only during the 1988/89 season (Table 2). Similarly, several other yield components were significantly correlated with drought grain yield only in the 1988/89 season (Table 2 ). The traits which were significantly correlated with drought grain yield during the 1988/89 season were significantly correlated with harvest index (Table 3 ), which suggests that in $1988 / 89$ grain yield was mainly sink determined. These results clearly show that traits that determine yield under low stress are different from those for severe drought. In all three years, drought grain yield was positively correlated with yield potential, confirming that drought yield is influenced by yield potential (Bidinger et al., 1987b).

The DRI was used for quantification of susceptibility and tolerance of a cultivar. The performance of a cultivar was characterized by the sign of DRI, a positive sign indicating that a cultivar is tolerant and a negative sign that it is susceptible (Bidinger et al., 1987b). A threshold value of DRI of 1.30 was, however, chosen as that which selects cultivars in the upper and lower $10 \%$ of the normal distribution of drought yields. A cultivar was considered non (zero) responsive to drought, if the absolute value in the drought treatment was smaller than $\pm 1.30 \mathrm{DRI}$ and responsive (have real response) if the absolute value under drought exceeded \pm 1.30 DRI (Bidinger et al., 1987b). The cultivar FLIP 83-2 was rated as tolerant and ICCL 82001 as susceptible in the $1986 / 87$ season with low temperatures, ILC 1919 as tolerant and FLIP 85-4 and ICCL 82001 as susceptible in the 1987/88 season with high rainfall, and Annigeri as tolerant and ILC 1272 as susceptible in the extremely dry $1988 / 89$ season (Table 4). Most of the cultivars rated as tolerant to drought had deep root systems and high pre-dawn leaf water potentials (Silim and Saxena, 1993). These results suggest that for areas with moderate levels of

TABLE 3

Correlations between harvest index ( $\mathrm{HI})$ and some of the traits during the $1988 / 89$ season

Trait

$\begin{array}{lc}\text { Straw yield }(\mathrm{kg} / \mathrm{ha}) & 0.700^{* * *} \\ \text { Pods } / \mathrm{m}^{2} & 0.921^{* * *} \\ \text { Seeds } / \mathrm{m}^{2} & 0.917^{* * *} \\ \text { l00-seed mass } & 0.434 \\ \text { Days to flowering } & -0.816^{* * *} \\ \text { Days to maturity } & -0.556^{* *}\end{array}$

Significance: ${ }^{*}=P<0.05 ; * * * P<0.001$. 
TABLE 4

Drought response index (DRI) for spring-sown chickpea cultivars at Tel Hadya, northern Syria during the 1987-1989 period

\begin{tabular}{lccr}
\hline Cultivar & $1986 / 87$ & $1987 / 88$ & $1988 / 89$ \\
\hline ILC 100 & NT & NT & -0.853 \\
ILC 262 & NT & NT & 0.526 \\
ILC 464 & 0.186 & -0.180 & -0.884 \\
ILC 624 & NT & NT & -0.749 \\
ILC 629 & 0.715 & 0.940 & -0.869 \\
ILC 1272 & NT & NT & -1.411 \\
ILC 1919 & 1.077 & 1.520 & 0.072 \\
ILC 1929 & NT & NT & -1.140 \\
ILC 1930 & 0.225 & 0.057 & -0.813 \\
FLIP 82-73 & 1.097 & 0.760 & -0.821 \\
FLIP 83-2 & 1.302 & 0.703 & 0.805 \\
FLIP 84-12 & -0.666 & -0.687 & NT \\
FLIP 84-74 & -0.774 & 0.572 & NT \\
FLIP 84-78 & -0.725 & -0.155 & NT \\
FLIP 84-80 & 1.116 & -1.234 & -0.255 \\
FLIP 85-4 & -0.018 & -1.602 & -0.964 \\
FLIP 85-49 & -0.911 & -0.384 & -0.925 \\
K 850 & NT & NT & -0.199 \\
ICC 4958 & -0.578 & 1.079 & 1.092 \\
ICC 10448 & 0.255 & 0.556 & 0.430 \\
ICC 10991 & 0.450 & -0.809 & 0.670 \\
ICCL 82001 & -1.753 & -1.504 & 0.040 \\
Annigeri & NT & 0.490 & 2.455 \\
\hline NT $=10110$ & & \\
\hline
\end{tabular}

NT $=$ not tested.

DRI $>+1.30=$ Cultivar is tolerant to drought.

$\mathrm{DRI}>-1.30=$ Cultivar is susceptible to drought.

stress (moisture and temperature), cultivars such as ILC 1919 and FLIP 832 are better adapted; and under severe stress as in 1988/89, the well-adapted cultivar is Annigeri.

The relative contribution of drought escape (early flowering), yield potential (yield in the fully irrigated treatment) and drought susceptibility or tolerance (characterized by DRI) to measured yield under drought, were evaluated by multiple regression. The contribution of each was expressed as percentage of the sum of squares it accounted for (Table 5). Drought escape was a major contributor to drought yield, particularly in the dry year, and accounted for 41,37 and $69 \%$ of the variations in 1986/87, 1987/88 and $1988 / 89$, respectively; yield potential for 47,37 and $1 \%$, respectively; and DRI for 4,17 and $17 \%$, respectively. The three factors combined explained on average $90 \%$ of the variability in grain yield under drought. This method of analysis thus provides an effective estimator of major factors that determine yield under drought. Drought response index (DRI) was positively and 


\section{TABLE 5}

Partitioning of sum of squares as percentage for drought yield (YNI) among time to flowering (FL), yield potential (YFI) and specific cultivar effect (DRI) in spring-sown chickpea

\begin{tabular}{lccc}
\hline & $1986 / 87$ & $1987 / 88$ & $1988 / 89$ \\
\hline FL & 41 & 37 & 69 \\
YFI & 47 & 37 & 1 \\
DRI & 4 & 17 & 17 \\
Residual & 8 & 9 & 13
\end{tabular}

\section{TABLE 6}

Correlations of yield and yield-related variables in drought stress treatment with time to flowering (drought escape $=\mathrm{FL})$ and drought response index $(\mathrm{DRI})$

Correlate

Correlation coefficient

FL DRI

$\begin{array}{lcc}1986 / 87 & & \\ \text { Biomass } & 0.464 & 0.106 \\ \text { Straw yield } & 0.641^{* * *} & -0.174 \\ \text { Harvest index } & -0.631^{* *} & 0.423 \\ \text { Grain yield } & -0.173 & 0.587^{*} \\ \text { Pods/m } \text { m }^{2} & -0.096 & 0.257 \\ \text { Seeds/m } & -0.100 & 0.314 \\ \text { Individual grain mass } & 0.203 & -0.004 \\ \text { Days to mature } & 0.823^{* * *} & 0.244 \\ \text { 1987/88 } & & \\ \text { Biomass } & 0.167 & 0.028 \\ \text { Straw yield } & 0.499^{*} & -0.239 \\ \text { Harvest index } & -0.709^{* * *} & -0.559^{*} \\ \text { Grain yield } & -0.431 & 0.561^{*} \\ \text { Pods/m } & -0.351 & 0.378 \\ \text { Seeds/m } & -0.328 & 0.328 \\ \text { Individual grain mass } & 0.147 & -0.142 \\ \text { Days to mature } & 0.813^{* * *} & -0.263 \\ \text { 1988/89 } & & \\ \text { Biomass } & -0.255 & 0.081 \\ \text { Straw yield } & 0.365 & -0.215 \\ \text { Harvest index } & -0.816^{* * *} & 0.650^{* *} \\ \text { Grain yield } & -0.842^{* * *} & 0.701^{* * *} \\ \text { Pods/m }{ }^{2} & -0.690^{* * *} & 0.660^{* *} \\ \text { Seeds/m } & -0.422 & 0.694^{* * *} \\ \text { Individual grain mass } & -0.655^{* * *} & -0.012 \\ \text { Days to mature } & 0.863^{* * *} & -0.222 \\ \text { Greatest rooting depth } & 0.075 & 0.657^{* *} \\ \text { Water potential at 77 DAS } & 0.237 & -0.482^{*} \\ \text { Water potential at } 84 \text { DAS } & 0.041 & -0.626^{* *}\end{array}$

${ }^{a} \mathrm{DAS}=$ days after sowing.

Significance: ${ }^{*} P<0.05 ; * * P<0.01 ; * * * P<0.001$. 
significantly correlated with drought grain yield $\left(0.587^{*}\right.$ in $1986 / 87,0.561^{*}$ in $1987 / 88$ and $0.701^{* * *}$ in $1988 / 89$ ) (Table 6), but not time to flowering and yield potential, confirming that its relationship to grain yield under drought was independent of the latter two factors.

\section{Identifying traits for drought escape and tolerance}

Analysis of the data indicates that drought escape expressed in this study as time to flowering was a major contributor to differences in drought yield and despite the low relative contribution of DRI, a few cultivars (with DRI > 1.30) exhibited real drought tolerance (Tables 4 and 5). The traits that were significantly correlated with drought yield were correlated with time to flowering and to DRI to determine whether they were associated with drought escape or tolerance/susceptibility to drought (Table 6). Separating traits correlated to yield under drought into escape (early flowering) or tolerance, provided an indication of those traits that are most useful as selection criteria for either drought escape or tolerance. High values of harvest index were clearly associated with drought escape, particularly under severe terminal drought (1988/ 89); additional traits associated with drought escape were production of a large number of pods $/ \mathrm{m}^{2}$ and high individual grain mass. Application, therefore, of these traits as selection criteria will identify many of the same lines identified using early flowering. Under the severe drought of $1988 / 89$, DRI was highly correlated with deep root systems, maintenance of high leaf water potentials and production of a large number of seeds $/ \mathrm{m}^{2}$ and not related to earliness (Table 6 ) and the former three, not the latter could be used as selection criteria for drought tolerance. Most of the cultivars identified as tolerant to drought using DRI had deep root systems (Silim and Saxena, 1993), which is consistent with the recommendations of Ludlow and Muchow (1988) for using that trait as a selection criterion for drought tolerance in sorghum and cowpea, and the correlation with high grain number is consistent with the report by Bidinger et al. (1987b) for terminal drought in pearl millet. The trait deep root system was exhibited under both drought and full irrigation and is, therefore, independent of moisture supply (Silim and Saxena, 1993). Maintaining high leaf water potential was most probably due to deep root systems that permitted continued water extraction. Similarly, production of large numbers of seeds was probably due to the ability of roots to extract water. Silim and Saxena (1993) earlier indicated that screening for deep root systems is laborious and suggested that a simple and indirect way to screen for deep root systems would be to select cultivars with high leaf water potential during reproductive growth. An additional trait to select would be production of high numbers of seeds under drought. 


\section{CONCLUSIONS}

The results of the present investigation clearly show that under severe terminal drought, as in $1988 / 89$, drought escape was the major contributor to high grain yield. Selection for early flowering is, therefore, an appropriate strategy if the intention is to breed for environments drier than the traditional chickpea growing areas of WANA. If, however, the intention is to develop chickpea cultivars for the traditional areas with mean annual rainfall of at least $400 \mathrm{~mm}$, and where variability from year to year is high, then DRI is an appropriate tool because it identifies cultivars and traits associated with drought tolerance.

\section{REFERENCES}

Acevedo, E. and Ceccarelli, S., 1989. Role of physiologist-breeder in a breeding program for drought resistance conditions. In: P.W.G. Baker (Editor), Drought Resistance in Cereals. Commonwealth Agricultural Bureaux (CAB), Wallingford, pp. 117-139.

Bidinger, F.R., Mahalakshmi, V. and Rao, G.D.P., 1987a. Assessment of drought resistance in pearl millet [Pennisetum americanum (L.) Leeke]. I. Factors affecting yield under stress. Aust. J. Agric. Res., 38: 37-48.

Bidinger, F.R., Mahalakshmi, V. and Rao, G.D.P., 1987b. Assessment of drought resistance in pearl millet [Pennisetum americanum (L.) Leeke]. II. Estimation of genotype response to stress. Aust. J. Agric. Res., 38: 49-59.

Blum, A., 1979. Genetic improvement of drought resistance in crop plants: a case of sorghum. In: H. Mussell and R.C. Staples (Editors), Stress Physiology in Crop Plants. Wiley Interscience, New York, NY, pp. 430-435.

Fischer, R.A. and Wood, J.T., 1979. Drought resistance in spring wheat cultivars. III. Yield associations with morphophysiological traits. Aust. J. Agric. Res., 30: 1000-1020.

Ludlow, M.M. and Muchow, R.C., 1988. Critical evaluation of the possibilities for modifying crops for high production per unit precipitation. In: F.R. Bidinger and C. Johansen (Editors), Drought Research Priorities of Dryland Tropics. International Crops Research Institute for the Semi-Arid Tropics (ICRISAT), Patancheru, India, pp. 179-211.

Quisenberry, J.E., 1982. Breeding for drought resistance and plant water use efficiency. In: N.M. Christiansen and F.C. Lewis (Editors), Breeding Plants for Less Favourable Environments. Wiley Interscience, New York, NY, pp. 192-212.

Richards, R.A., 1982. Breeding and selecting for drought in wheat. In: Drought Resistance in Crop Plants with Emphasis on Rice. IRRI, Los Baños, Philippines, pp. 303-316.

Saxena, M.C., Silim, S.N. and Singh, K.B., 1990. Effect of supplemental irrigation during reproductive growth on winter and spring chickpea (Cicer arietinum) in a Mediterranean environment. J. Agric. Sci. (Camb.), 114: 285-294.

Silim, S.N. and Saxena, M.C., 1992. Comparative performance of faba bean (Vicia faba) plant types. 1. Yield, yield components and nitrogen fixation. J. Agric. Sci. (Camb.), 118: 325332.

Silim, S.N. and Saxena, M.C., 1993. Adaptation of spring-sown chickpea to the Mediterranean basin. I. Response to moisture supply. Field Crops Res., 34: 121-136.

Silim, S.N., Saxena, M.C. and Erskine, W., 1993. Adaptation of lentil to the Mediterranean environment. I. Factors affecting yield under drought conditions. Exp. Agric., 29: 9-19.

Turner, N.C., 1982. The role of shoot characteristics in drought resistance. In: Drought Resistance in Crops with Emphasis on Rice. IRRI, Los Baños, Philippines, pp. 115-34. 